Dicle Tıp Dergisi / Dicle Med J (2019) 46 (3) : 553 - 557

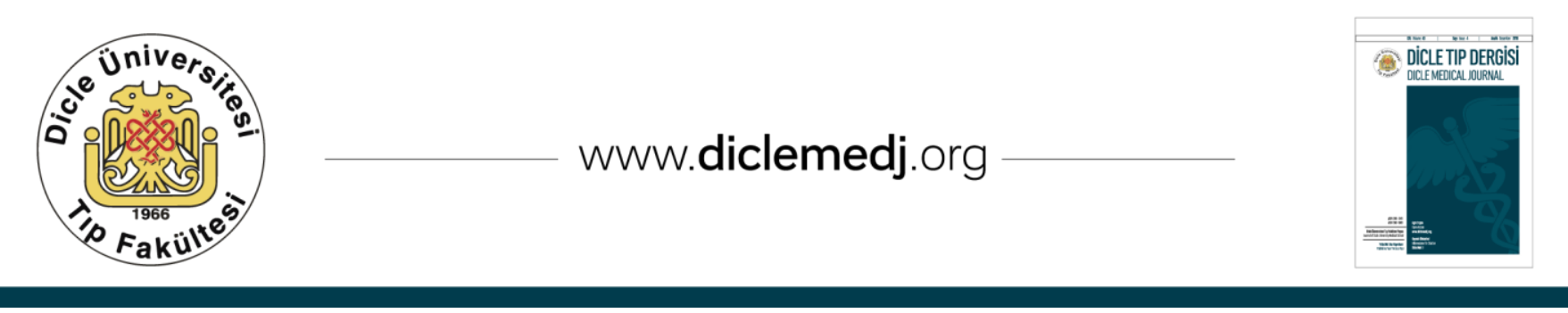

Özgün Araștırma / Original Article

\title{
Anti-TNF alfa kullanan hastalarda hepatit B reaktivasyonunun değerlendirilmesi
}

\author{
İkay Bozkurt ${ }^{1}$, Ahmet Bektaş² \\ 1 Ondokuz Mayıs Üniversitesi Tıp Fakültesi Enfeksiyon Hastalıkları ve Klinik Mikrobiyoloji AD, ORCID: 0000-0002-8425-9719 \\ 2 Ondokuz Mayıs Üniversitesi Tıp Fakültesi Gastroenteroloji AD, ORCID: 0000-0001-7026-9353
}

Geliş: 11.07.2019; Revizyon: 19.08.2019; Kabul Tarihi: 19.08.2019

Öz

Amaç: Anti-tümör nekrozis faktör alfa (anti-TNF) alfa kullanan HBsAg pozitif hastalarda profilaksi önerilmektedir. HbsAg (-), anti-HBcIgG ( +/-) ve anti-HBsIgG (-)hastalarda ise hepatit B profilaksisi tartışmalıdır. Bu çalışmada antiTNF alfa kullanan hastalarda HBV tarama oranı ve reaktivasyon sıklığının saptanması amaçlanmıştır.

Yönetmler: Çalışma tek merkezde retrospektif olarak yürütülmüştür. Farklı endikasyonlarla anti-TNF alfa kullanan hastalarda tedavi öncesi hepatit B göstergeleri (HBsAg, anti-HBcIgG, anti-HBs) ile viral yük tetkik sonuçları elektronik dosya kayıtlarından taranmıştır.

Bulgular: Farklı endikasyonlarla anti-TNF alfa kullanan 644 hasta çalıșmaya alınmıştır. Bu hastaların 410'u (\%63,7) tedavi öncesinde hepatit B açısından taranmıştır. (410 hastanın 17'si HBsAg (+) (grup 1), 39'u HBsAg (-), anti-HBs(+) ve anti-HBcIgG (+) (grup 2), 15'i izole anti-HBcIgG (+) (grup 3), 339'u viral göstergeleri negatif (grup 4) olarak saptanmıştır). Hastalar ortalama 28 ay süreyle takip edilmiștir. Grup 1 hastaların 13'ü (\%76), grup 2 ve 3'deki hastaların ise 48'i $(\% 88,9)$ reaktivasyon açısından takip edilmiştir. Grup 2 ve 3'deki hastaların hiçbirisinde takiplerinde HBV reaktivasyonu gelişmezken, grup 1 hastalarının birinde reaktivasyon gelişmiştir. Anti-TNF öncesinde tarama yapılmayan bir hastada da reaktivasyon tespit edilmiştir.

Sonuç: Anti-TNF alfa alan hastaların reaktivasyon açısından tarama ve takibinin doğru zamanda ve uygun testlerle yapılması ve hastaların yakın izlemi gerekmektedir.

Anahtar kelimeler: Hepatit B, Anti-TNF alfa, Hepatit B reaktivasyonu. 


\title{
Evaluation of hepatitis B reactivation in patients receiving anti-TNF alpha
}

\begin{abstract}
Objective: Prophylaxis is recommended in HBsAg positive patients receiving anti-TNF alpha. HBV prophylaxis is controversial in HbsAg (-), anti-HBc IgG (+) and anti-HBs IgG (+/-) patients. The aim of this study was to determine HBV screening rate and reactivation frequency in patients receiving anti-TNF alpha.

Methods: The study was conducted retrospectively in a single center. Hepatitis B markers (HBsAg, anti-HBcIgG, antiHBs) and viral load results were screened from electronic file records in patients who were treated with anti-TNF alpha for different indications.

Results: Sixty-four patients using anti-TNF alpha for different indications were included in the study. 410 (63.7\%) of these patients were screened for hepatitis B before treatment. (Of the 410 patients, 17 were HBsAg (+) (group 1), 39 were HBsAg (-), anti-HBs(+) and anti-HBc IgG (+) (group 2), 15 isolated anti-HBc IgG (+) (group 3), 339 were marker negative (group 4). Patients were followed for a mean of 28 months. 13 (76\%) of the patients in group 1 and 48 (88.9\%) of the patients in group 2 and 3 were followed for reactivation. None of the patients in group 2 and 3 developed HBV reactivation during follow-up, while one of the patients from group 1 developed reactivation. Reactivation was also detected in one patient who had not been screened prior to anti-TNF therapy.

Conclusion: Screening and follow-up of patients receiving anti-TNF alpha in terms of reactivation should be performed at the right time with appropriate tests and close monitoring of the patients is required.
\end{abstract}

Keywords: Hepatitis B, Anti-TNF alpha, Hepatitits B reactivation.

\section{GíRiş}

Hepatit B virüsü (HBV) kronik hepatit, siroz ve hepatoselüler kansere yol açmaktadır. Ülkemiz hepatit B açısından orta endemik bölgeler arasındadır.Ülkemizde HBsAg pozitifliği \%4 civarında iken anti-HBclgG pozitifliği $\% 30,6$ oranındadır ${ }^{1}$. Yeni biyolojik ajanlardan olan anti-tümör nekrozis faktör alfa (anti-TNF alfa) kullanımı son yıllarda giderek artmakta ve romatoidartrit, ankilozanspondilit, inflamatuar barsak hastalığı, Behçet hastalığı ve psöriazis bașta olmak üzere farklı endikasyonlarda kullanım alanı bulmaktadır. Birçok hastalık için tedavi alternatifi olurken, HBV reaktivasyonu açısından riskli ilaçlar oldukları bilinmektedir ${ }^{2,3}$.

Anti-TNF alacak hastaya uygun endikasyonda antiviral verilmezse HBV reaktivasyonuna bağlı olarak sarılık, karaciğer yetmezliği ve ölüm gelişebilir4. Güncel rehberler anti-TNF alfa alacak HBsAg pozitif hastalara potentantivirallerle profilaksi önermektedir ${ }^{1}$. HBsAg (-), anti-HBcIgG ( \pm antiHBs) pozitifliği durumunda ise profilaksi açısından fikir birliği yoktur.

İmmünsüpresif tedavi öncesinde bu hastaların serolojik olarak taranması mutlaka önerilmesine rağmen pratikte aksamalar dikkat çekmektedir. Bu çalışmada hastanemizde antiTNF alfa kullanan hastalarda HBV tarama oranı ve reaktivasyon riskinin değerlendirilmesi amaçlanmıștır.

\section{YÖNTEMLER}

Çalışma 1 Ocak 2012 ile 31 Aralık 2016 yılları arasında anti-TNF alfa başlanan hastalar retrospektif olarak incelenmiş̦tir. Çalışma için Ondokuz Mayıs Üniversitesi Klinik Araştırmalar Etik Kurulu onayı alınmıştır. Çalışmaya $\geq 18$ yaş hastalar alınmış olup hastaların yaş, cinsiyet, tanı, HBsAg, anti-HBs, anti-HBcIgG, PCR HBVDNA ile tarama vetakip süreleri değerlendirilmiștir. HBsAg ve/veya antiHBcIgG pozitif olan hastalarm antiviral profilaksi alıp almaması yönünden kayıtları incelenmiştir. Reaktivasyon, HBsAg pozitif 
hastalarda HBV DNA negatifken pozitifleşmesi, HBV DNA'sı daha önceden pozitif olan hastada $\geq 1$ log artış olması veya HBV DNA yükselen hastada ALT'de 3 kat artış veya ALT $\geq 100$ IU/mL olması, HBsAg negatif olup anti-HBcIgG pozitif olan hastalarda ise reaktivasyonserokonversiyon gelişmesi ile HBsAg'ninpozitifleşmesi, HBV DNA'nıntespit edilebilir düzeye çıkması ve/veya reaktivasyon sonucu biyokimyasal hepatit gelişmesi olarak tanımlanmıştır (5).

İstatistiki analiz IBM SPSS v21. kullanılarak yapılmıştır. HBV tarama, antiviralprofilaksi kullanımı ile reaktivasyon oranları frekans ve oran olarak sunulmuştur.

\section{SONUÇLAR}

Anti-TNF alfa kullanıp çalışmaya alınan 644 hastanın 369'u (\%57,3) erkek, 275 (\%42,7)'i kadın, median yaş 44 (20-85) yıl idi. Hastaların anti-TNF alfa tedavi endikasyonları tablo 1'de verilmiştir. Hastaların kullandıkları anti-TNF alfa ilaçlar sırasıyla; adalimumab $(n=241)$, infliximab $(n=184)$, etanercept $(n=126)$ ve golimumab (n=93)'dir. Hastaların alt hastalıklarına göre dağılımları Tablo 1'de verilmiştir.

Tablo 1. Anti-TNF endikasyonuna göre tanıların dağılımları

\begin{tabular}{ll}
\hline Tanı & Hasta Sayısı $(\%)$ \\
\hline Psoriazis & $211(32,8)$ \\
\hline Ankilozan spondilit & $171(26,5)$ \\
\hline İnflamatuvar barsak hastalıkları & $107(16,6)$ \\
\hline Romatoidartrit & $73(11,3)$ \\
\hline Behçet Hastalığı & $65(10,1)$ \\
\hline Hidradenitissuppurativa & $6(0,9)$ \\
\hline Takayasu arteriti & $5(0,8)$ \\
\hline Herediteramiloidoz & $4(0,6)$ \\
\hline Pulmonersarkoidoz & $1(0,16)$ \\
\hline Karaciğer transplantasyonu & $1(0,16)$ \\
\hline
\end{tabular}

İmmünsüpresif tedavi öncesinde 644 hastanın 410'u $(\% 63,7)$ HBV açısından taranmıştır. Hastaların 234'ünün $(\% 36,3)$ ise HBV açısından serolojik durumu bilinmiyordu. HBV taraması yapılan hastaların 17'si HBsAg pozitif (grup 1), 39'u HBsAg negatif, anti-HBs ve anti-HBcIgG pozitif (grup 2), 15'i izole anti-HBclgG pozitif (grup 3), 339'u hepsi negatif (grup 4) olarak saptanmıştır). Hastalar ortalama 28 ay süreyle takip edilmiştir.Grup 1 hastaların 13'ü (\%76), grup 2 ve 3 hastaların ise 48'i $(\% 88,9)$ reaktivasyon açısından takip edilmiştir.

Tablo 2. Hepatit B taraması yapılan hastaların sonuçları.

Öz

\begin{tabular}{|c|c|}
\hline \multirow{3}{*}{$\begin{array}{c}\text { HBV taraması yapılan hasta sayısı (N) } \\
\text { • } \\
\text { • } \\
\text { - } \quad \text { Yinsiyet (erkek) } \\
\text { (median, yıl) }\end{array}$} & $410(63,6)$ \\
\hline & $240(58,5)$ \\
\hline & $45(20-85)$ \\
\hline \multicolumn{2}{|l|}{ Serolojik göstergelerine göre grupların dağılımı } \\
\hline - $\quad$ Grup $1(\operatorname{HBsAg}(+))$ & $17(4,1)$ \\
\hline \multirow{2}{*}{$\begin{array}{l}\text { - } \operatorname{Grup} 2(\operatorname{HBsAg}(-), \text { anti-HBs }(+) \text {, anti- } \\
\text { HBcIgG }(+))\end{array}$} & $39(9,5)$ \\
\hline & \\
\hline \multirow{2}{*}{$\begin{array}{l}\text { Grup } 3(\operatorname{HBsAg}(-) \text {, anti-HBs }(-) \text {, anti- } \\
\text { HBcIgG }(+))\end{array}$} & $15(3,7)$ \\
\hline & \\
\hline \multirow{2}{*}{$\begin{array}{l}\text { - } \quad \text { Grup } 4 \text { (HBsAg }(-) \text {, anti-HBs }(-) \text {, anti- } \\
\text { HBcIgG }(-))\end{array}$} & $339(82,7)$ \\
\hline & \\
\hline
\end{tabular}

HBV profilaksisi yapılan hasta sayısı (\%)

- $\quad$ Grup 1

$15(88,2)$

- Grup 2

$16(41)$

- $\quad$ Grup 3

$8(53,3)$

HBV reaktivasyonu (profilaksi verilen ve yapılmayan)
- $\quad$ Grup 1
$1(5,8)$
- $\quad$ Grup 2
$0(0)$
- $\quad$ Grup 3
$0(0)$

Grup2 ve3'te yer alan hastaların 48'i $(\% 88,9)$ kontrollerinde HBV serore versiyonu açısından takip edilmiştir. Hiçbirisinde HBsAg pozitifliği tespit edilmemiştir. Hastaların 14(\%25.9)'unun başlangıç HBV DNA'sına bakılmış ve hepsi negatif olarak tespit edilmiştir. Anti-HBcIgG 
pozitif 54 hastanın 27 (\%50)'sine profilaksi (tenofovir( $n=18)$ Entekavir $(n=4)$ ve Lamivudin $(n=5)$ verilmiştir. Tedavi verilen ve verilmeyen hiçbir hastanın takibinde reaktivasyon gelişmemiştir (Tablo 2).

HBsAg pozitif 17 hastanın 5'i kronik hepatit tanısı ile takip edilirken, 12'si karaciğer enzimleri normal ve HBV DNA'ları <2000IU/ml olan inaktif HBsAg taşıyıcısı idi. Hastaların 13 (\%76)'ü poliklinik takiplerinde kontrol viral yük ile reaktivasyon açısından takip edilmiştir. İki hasta dışında HBsAg pozitif olan tüm hastalara antiviralprofilaksi başlanmıştır. Profilaksi almayan iki hastanın da sonraki takipleri olmadığı için reaktivasyon açısından akıbetleri bilinmemektedir.

Grup 1'deki hastaların sadece birinde reaktivasyon gelişmiştir. Bu hasta 44 yaşında kronik hepatit B tanısı ile 9 yıldır tenofovir kullanan, ankilozanspondilit tanısı ile adalimumab başlanan hastadır. Geçmiş anamnezinden antiviral tedaviyi bıraktığı öğrenilmiştir. Hastaya tenofovir tedavisi tekrar başlandıktan bir ay sonra viral yükü tekrar negatifleşmiştir. Psöriazis tanısıyla anti-TNF alfa alan, öncesinde HBV taraması yapılmayan bir hastada transaminaz yüksekliği gelişmiş, tetkiklerde HBV reaktivasyonu saptanmıştır. Tenofovir tedavisinden sonra viral yük negatifleșmiş, transaminazlar normal düzeylere inmiştir.

\section{TARTIŞMA}

Anti-TNF kullanımının HBV reaktivasyonu açısından risk oluşturmasındaki en önemli neden sitotoksik $\mathrm{T}$ lenfositler tarafindan üretilen TNF alfa'nın HBV replikasyonunu önleyici etkisinin ortadan kalkmasıdır ${ }^{2}$. Reaktivasyonu engellemek için ilk öneri tedavi öncesi uygun taramanın yapılması, ikinci olarak da hastanın serolojik durumu ve viral yükü göz önünde bulundurularak immünsüpresif ajandan 1-3 hafta önce antiviralprofilaksi başlanmasıdır ${ }^{1}$. Tarama bizim hasta grubumuzda \%63,7 oranında yapılabilmiştir.
HBsAg pozitif olgulara \%88,2, anti-HBc pozitifliği olan olgularda ise $\% 50$ oranda antiviral profilaksi verilmiştir.

HBV reaktivasyonu özellikle HBsAg pozitif hasta grubunda yüksek insidansta rapor edilmiștir (6). Reaktivasyon riski yüksek viral yükü olan kronik hepatit B'li hastalarda inaktif HBsAg taşıyıcılarına göre daha yüksektir ${ }^{1,6}$. Çalışmamızda biri kronik hepatit B hastası, biri de başlangıç viral taraması yapılmamış muhtemel kronik hepatiti olan bir hastada reaktivasyon gelişmiştir.

Amerikan Gastroenteroloji Derneği HBsAg(+) veya $\quad \mathrm{HBsAg}(-) /$ anti-HBc(+) hastalara immünsüpresif kesildikten sonraki 6 aya kadar antiviral profilaksi önermektedir. Ülkemizden yapılan uzlaşı raporunda ise $\mathrm{HBsAg}(+)$ hastalara profilaksi önerilirken HBsAg(-)/anti$\mathrm{HBc}(+)$ hasta grubunda HBV DNA negatifse üç ayda bir HBV DNA kontrolü önermektedir ${ }^{1,7}$. Bu çalışmada anti-HBcIgG pozitif hastaların \%50'sine profilaksi verilmiş, \%50'sine de verilmemiş olmasına rağmen hiçbir hastada HBV reaktivasyonu gözlenmemiştir. Literatürde de benzer şekilde anti-HBc pozitif hasta grubunda alevlenmenin hiç gerçekleşmediği çalışmalar sunulmuştur ${ }^{8,9}$. Chiu YM. ve arkadaşlarının ${ }^{9}$ yaptıkları kapsamlı kohortta anti-TNF alan ve HBsAg(-)/anti$\mathrm{HBc}(+) 282$ hasta benzer sayıdaki ve aynı serolojideki ancak anti-TNF maruziyeti olmayan hastalarla karşılaştırılmış ve HBsAg()/anti-HBc(+)hasta grubunda anti-TNF'lerin güvenli olduğu sonucuna varmışlardır.

Perez Alverez R. ve arkadaşlarının ${ }^{3}$ çalışmasında anti-HBc pozitif hastalarda \%5 oranında reaktivasyon bildirilmiştir ancak reaktivasyon gelişen hastaların hiçbirinin başlangıç viral yükleri ve anti-HBs durumları bilinmemektedir. Başka bir nokta ise en erken reaktivasyon yaklaşık bir yıl sonra gelişmiş olup bu sürede viral yükte pozitifleşme olup olmadığ 1 bilinmemektedir ${ }^{3}$. Reaktivasyonun hasta, hekim ve immünsüpresif ajan ayağl 
vardır ${ }^{10,11}$. Hastanın bilgilendirilmesi, hekimin konu ile ilgili yeterli eğitim alması ve anti-TNF alfa tedavisi öncesinde de gerekli göstergelerle hastaların taranması ve belirli aralıklarla izlenmesi önerilmektedir ${ }^{10,11}$.

Çalışmamızın retrospektif olması bir kısıtlılık olmakla birlikte son derece değerli veriler ortaya konmuştur. Hastalarımızın ancak üçte ikisini tarayabilmişiz ki immünsüpresif hastaların tümü tedavi öncesinde mutlaka hepatit B açısından taranmalıdır. İki hastada reaktivasyon gelişmiştir ki bu da taramanın ardından takibin mutlaka yapılması gerektiğini göstermektedir.

Anti-HBc pozitif hastaların hiçbirisindeanti-HBs sonuçlarından bağımsız olarak reaktivasyon gelişmemiştir ki bu hasta grubunda antiviral kullanım oranı \%50'dir. Anti-HBc pozitif hastalar başlangıçta HBV DNA açısından da tetkik edilmeli ve üç ayda bir kontrollerde viral yük tayini yapılmalıdır. Anti-HBs negatifse hastalar aşılanmalıdır. $\mathrm{Bu}$ hasta grubunda antiviral gerekliliği sorgulanmalıdır. Prospektif olarak düzenlenecek lokal rehberler ışığında tarama ve takip programları oluşturularak çok sayıda hasta içeren çalışmalar bu konuda daha aydınlatıcı olacaktır.

Çıkar Çatışması Beyanı: Bu çalışmada çıkar çatışması yoktur.

Finansal Destek: Bu çalışma herhangi bir fon tarafından desteklenmemiştir.

Declaration of Conflicting Interests: There is no conflict of interest in thisstudy.

Financial Disclosure: No financial support was received.

\section{KAYNAKLAR}

1. Aygen B, Demir AM, Gümüş $M$, et all. Immuno suppressive ther apyandthe risk of hepatitis $B$ reactivation: Consensusreport. Turk J Gastroenterol. 2018; 29: 259-69.
2. Ye $H$, Zhang $X W, M u ~ R$, et all. Anti-TNF therapy in patientswith HBV infection--analysis of 87 patients with in flammatory arthritis. Clin Rheumatol. 2014; 33: 119-23.

3. Pérez-Alvarez R, Díaz-Lagares C, García-Hernández F, et all. Hepatitis $B$ virus (HBV) reactivation in patients receiving tumornecrosis factor (TNF)-targeted therapy: analysis of 257 cases. Medicine (Baltimore). 2011; 90: 359-71.

4. Tavakolpour S, Alavian SM, Sali S. Hepatitis B Reactivation During Immuno suppressive Therapyor Cancer Chemotherapy, Management, and Prevention: A Comprehensive Review. HepatMon. 2016; 16: e35810.

5. Pattullo V. Prevention of Hepatitis B reactivation in thesetting of immunosuppressionClinMolHepatol. 2016; 22: 219-37.

6. Nard FD, Todoerti M, Grosso V, et all. Risk of hepatitis $\mathrm{B}$ virusreactivation in rheumatoidarthritispatientsu nder going biologictreatment: Extending perspective from oldtonewerdrugs. World J Hepatol. 2015; 7: 344-61.

7. Reddy KR, Beavers KL, Hammond SP, Lim JK, FalckYtter YT. American Gastroenterological Association Institute guideline on the prevention and treatment of hepatitis B virus reactivation during immuno suppressivedrug therapy. Gastroenterology. 2015; 148: 215-9.

8. Chiu YM, Lai MS, Chan KA. Commen surate in cidence and outcomes of liverenzyme elevation between antitumornecrosis factorusers with orwith outpriorhepatitis B virusinfections. PLoSOne. 2018; 13: e0196210.

9. Biondo MI, Germano V, Pietrosanti M, et all. Lack of hepatitis $B$ virus reactivation after antitumournecrosis factor treatment in potentialoc cultcarriers with chronic in flammatory arthropathies. Eur J Intern Med. 2014; 25: 482-84.

10. Clarke WT, Amin SS, Papamichael K, Feuerstein JD, Cheifetz AS. Patients with core antibody positive and surfaceantigen negative Hepatitis B (anti-HBc+, HBsAg-) on anti-TNF therapyhave a low rate of reactivation. ClinImmunol. 2018; 191: 59-62.

11. Cannizzaro MV, Franceschini C, Esposito M, Bianchi L, Giunta A. Hepatitis Breactivation in psoriasispatientstreated with anti-TNF agents: prevention and management. Psoriasis (Auckl). 2017; $7: 35-40$. 